
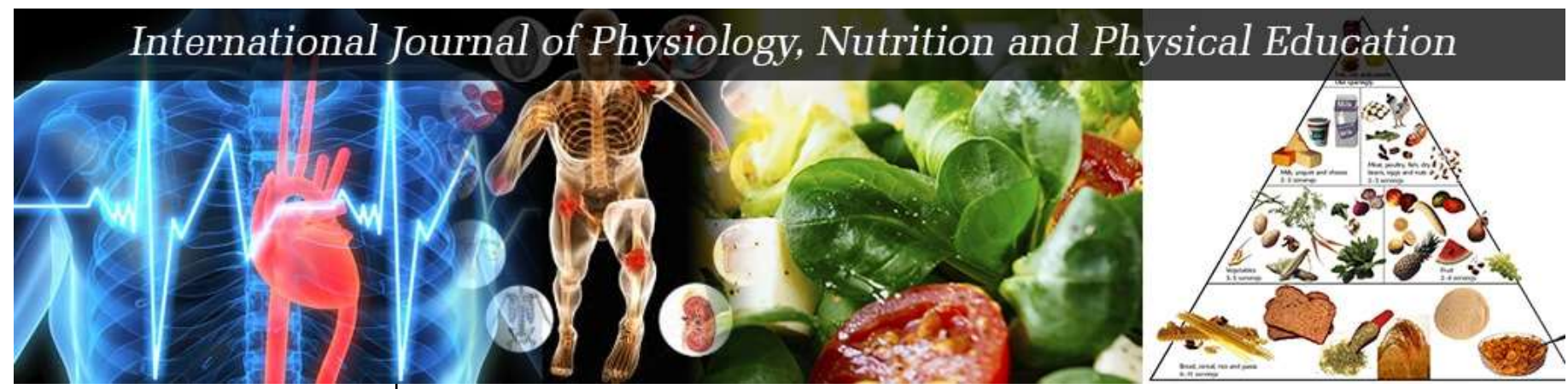

ISSN: 2456-0057

IJPNPE 2021; 6(1): 79-84

(C) 2021 IJPNPE

www.journalofsports.com

Received: 09-11-2020

Accepted: 13-12-2020

Parul Tyagi

Sports Nutritionist, High

Performance Lab, Sports

Authority of India, Delhi, India

G Vani Bhushanam

Junior Scientific Officer

(Nutrition), High Performance

Lab, Sports Authority of India,

Delhi, India
Corresponding Author: Parul Tyagi

Sports Nutritionist, High

Performance Lab, Sports

Authority of India, Delhi, India

\section{A comparative study on the macronutrient intake of elite Indian female weightlifters and boxers}

\section{Parul Tyagi and G Vani Bhushanam}

DOI: https://doi.org/10.22271/journalofsport.2021.v6.i1b.2175

\section{Abstract}

Weightlifting \& Boxing are weight specific power events which involves high intensity training. Nutrient supply for fueling body stores as well as maintenance of body weight for the desired category is of utmost importance. This study is aimed to assess the energy and macro nutrient intake of elite female Weightlifters \& Boxers of SAI and to compare with recommendation of NIN (National Institute of Nutrition) \& SAI (Sports Authority of India). Out of a total of 45 sports persons, 22 were weightlifters \& 23 were boxers. The compression between sports has been made based on weight category of heavy, middle \& light. A questionnaire and $24 \mathrm{hr}$ dietary recall were used to collect data. The mean energy intake was $2835+532.91,2834.66+417.18,2595.33+444.93 \mathrm{kcal}$ in boxers of heavy, middle \& light weight categories respectively. The mean energy intake was $4789.82+787.36,4335.3+836.70 \&$ $3372.18+826.13 \mathrm{k}$.cal in weightlifters of heavy middle \& light weight categories respectively. The comparison of percentage adequacy with NIN recommendations showed fairly adequate among all weight categories of weightlifters and inadequate among all weight categories of boxers. The mean percentage carbohydrate intake of total energy was 56\%, 55\% and 51\% in heavy, middle and light respectively in boxers and $37 \%, 47 \%$ and $50 \%$ in heavy, middle and light respectively in weightlifters. The carbohydrate intake was low in weightlifters of all categories in comparison with boxers against recommendation. On the contrary, in boxing the carbohydrate intake was low only in light weight category. The protein intake was high in all categories of weightlifters compared to boxers and the recommended value. The protein intake was adequate in middle weight category boxers and moderate in high \& light weight category boxers. Mean percentage fat intake of total energy was $26 \%, 24 \% \& 28 \%$ in heavy, middle and light weight categories respectively among weightlifters and $31 \%, 30 \%$ \& $26 \%$ in heavy, middle and light weight categories respectively among boxers. The intake of fat was high in weightlifting in all weight categories and in boxers it was high in middle \& light weight categories. Adequate nutritional counselling is required to address the nutrient intake to the players for optimizing their performance.

Keywords: Boxing, weightlifting, 24-hour dietary recall, macronutrient intake

\section{Introduction}

Dietary practices have a profound impact on athlete health and performance ${ }^{[1,2]}$. Due to increased physical demands, athletes achieve daily energy expenditures that require aboveaverage energy and macronutrient intakes to sustain training, enhance recovery, and maintain performance [1]. Dietary intake should match energy expenditure to maintain health and performance and evidence to support this has been reviewed ${ }^{[1,3,4]}$. Specifically, an inadequate energy intake (EI) is harmful to performance, bone health ${ }^{[5,6]}$, cognition ${ }^{[7]}$, and mood ${ }^{[7]}$.

Nutrient supply for fueling body stores as well as maintenance of body weight for the desired category is of utmost importance ${ }^{[11]}$. In accordance of nutrition and hydration guidelines set under the collaboratio of Indian life science institute (ILSI), National Institute of Nutrition (NIN) and Sports Authority of India (SAI) classified sports events into five categories and the recommended energy allowances for Indian athletes should be based on the energy expenditure levels as suggested by FAO/WHO/UNO (1985). They also classify the weight categories, into heavy, middle and light weight categories and the nutritional recommendations are based on average body weight for these category ${ }^{[3]}$. Boxing, wrestling, judo \& weightlifting are the sports that fall under weight control category. Unfortunately, most coaches and athletes are not well informed on nutritional and weight control techniques and are following unrealistic means ${ }^{[3]}$. 
Eating habits may outline the athlete's performance. Several factors should be considered in order to plan a suitable nutritional planning, among them the caloric content of the diet, the macronutrients distribution and the supply of adequate quantities of vitamins and minerals ${ }^{[11]}$. Moreover, the athlete's diet should be established according to individual needs, frequency and training intensity and duration ${ }^{[8]}$. Generally, eating distribution are not uniform among athletes, what actually occurs is an expected behaviour of deficiencies according to the modality evaluated, especially fights ${ }^{[9]}$.

Therefore, the aim of this study was to quantify energy and macronutrients intake of elite level athletes and compare with recommendations. Secondary aim was to compare dietary intake between boxers and weightlifters as the recommendation for both the athletes are same.

\section{Methodology}

This study was aimed to assess macro nutrient intake of elite female Weightlifters \& Boxers of SAI (sports authority of India). Out of a total 45 participants, 22 were weightlifters \& 23 were boxers. The comparison between sports has been made based on weight category of heavy, middle \& light. A questionnaire and 24-hour dietary recall were used to collect data.

A cross-sectional design was used to quantify relationship among athlete's dietary intake. The nutritional status of the athletes was diagnosed through qualitative and quantitative evaluation of the ingested food, 24 hour diet record ( 3 days). Recipes were standardized as all athletes were having food at training centre. The dietary intake data obtained with the 24hour records was changed into energy and nutrients indices through India food composition tables $2010^{[18]}$. The intake suitability of macronutrients was calculated based on the Reference NIN (National Institute of Nutrition) \& SAI (Sports Authority of India).

\section{Statistical analysis}

Data coding, entry and validation was done and total Energy ( $\mathrm{kcal} / \mathrm{d}$ and $\mathrm{kcal} / \mathrm{kg} / \mathrm{d})$, Carbohydrate (\% of energy and $\mathrm{g} / \mathrm{kg} / \mathrm{d}$ ), Protein (\% of energy and $\mathrm{g} / \mathrm{kg} / \mathrm{d}$ ) and Fat (\% of total energy) were calculated. 24-hour dietary recall questionnaire were used to determine energy and macronutrient intake of national level female weightlifters \& boxers. Their daily intake was compared to Recommended NIN\& SAI guidelines. Nutrient Adequacy and Nutrient Adequacy Ratio were calculated. A p-value of $<0.05$ and $<0.001$ were used to determine statistical significance. SPSS and Microsoft excel were used to complete all statistical analysis. All normally distributed data are presented as mean, standard deviation. Paired sample t-test was used to assess difference between groups and ANOVA test used to assess difference within the group.

\section{Results}

Table 1: Comparative table of energy intake of weightlifters with the NIN recommendation and their percentage adequacy ratio

\begin{tabular}{|c|c|c|c|c|}
\hline S. No. & Weight category & NIN* Recommendation (Kcal) & Calculated intake + S.D. (Kcal) & \% Adequacy \\
\hline 1. & Heavy Weight & 6000 & $4789.82+787.36$ & $80 \%$ \\
\hline 2. & Middle weight & 4500 & $4335.50+836.70$ & $96 \%$ \\
\hline 3. & Light weight & 3600 & $3372.18+826.70$ & $94 \%$ \\
\hline
\end{tabular}

Table 1. Show the energy intake of weightlifters which was compared with NIN recommendations. The mean energy intake was calculated $4789.82+787.36 \mathrm{kcal}, 4335.30+$ 836.70k.cal and $3372.18+826.70 \mathrm{k} . c a l$ in heavy, middle and light weight category respectively. The comparison of percentage adequacy with NIN recommendations showed fairly adequate among all weight categories of weightlifters.

Table 2: Comparative table of energy intake of boxers with the NIN recommendation and their percentage adequacy

\begin{tabular}{|c|c|c|c|c|}
\hline S. No. & Weight category & NIN* Recommendation (Kcal) & Calculated intake + S.D. (Kcal) & \% Adequacy \\
\hline 1. & Heavy Weight & 6000 & $2835+532.91$ & $47 \%$ \\
\hline 2. & Middle weight & 4500 & $2834.66+417.18$ & $63 \%$ \\
\hline 3. & Light weight & 3600 & $2335.8+471.92$ & $65 \%$ \\
\hline
\end{tabular}

Table 2 shows the energy intake which was compared with NIN recommendations. The mean energy intake was calculated $2835+532.91 \mathrm{kcal}, 2834.66+417.18 \mathrm{k}$.cal and $2335.8+471.92 \mathrm{k}$.cal in heavy, middle and light weight category respectively. The comparison of percentage adequacy with NIN recommendations showed inadequate energy intake among heavy weight category \& moderate among middle and light weight categories. 


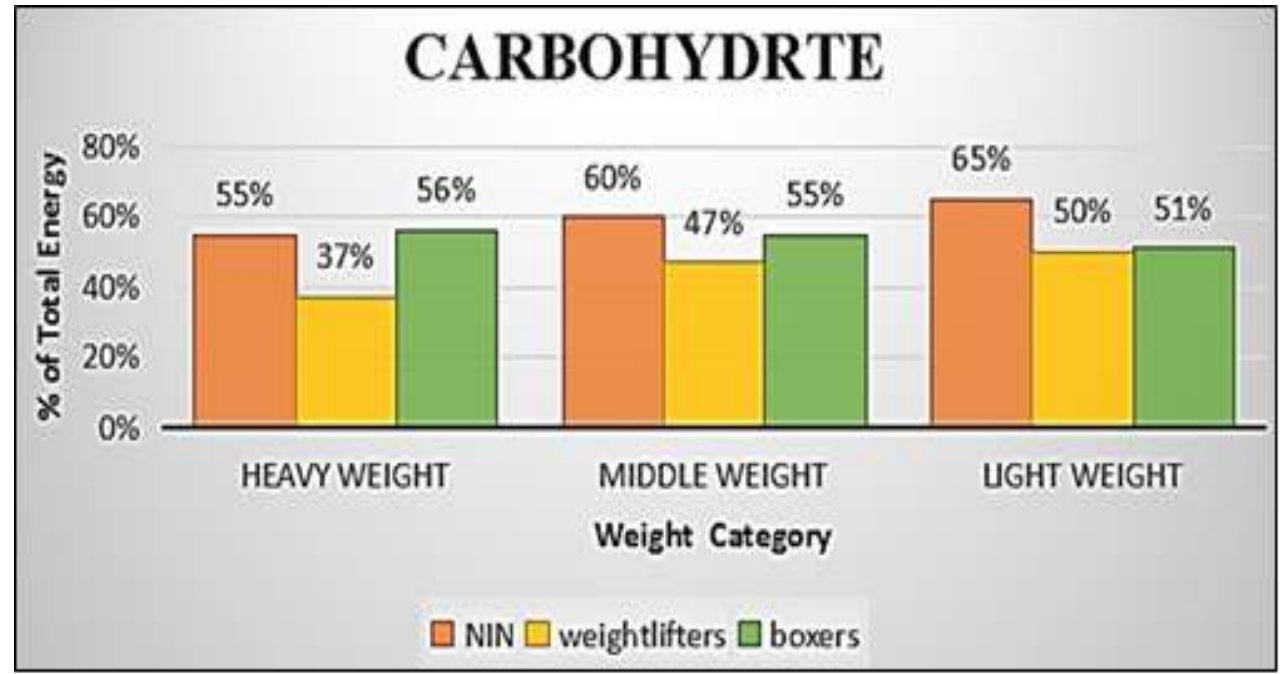

Fig 1: Mean percentage of carbohydrate intake of total energy of boxers and weightlifters with the NIN recommendation

Figure-1 show the mean percentage carbohydrate intake of total energy was low in all weight category of weightlifters in comparison with boxers against recommendation on the contrary it was low in light weight category of boxers.

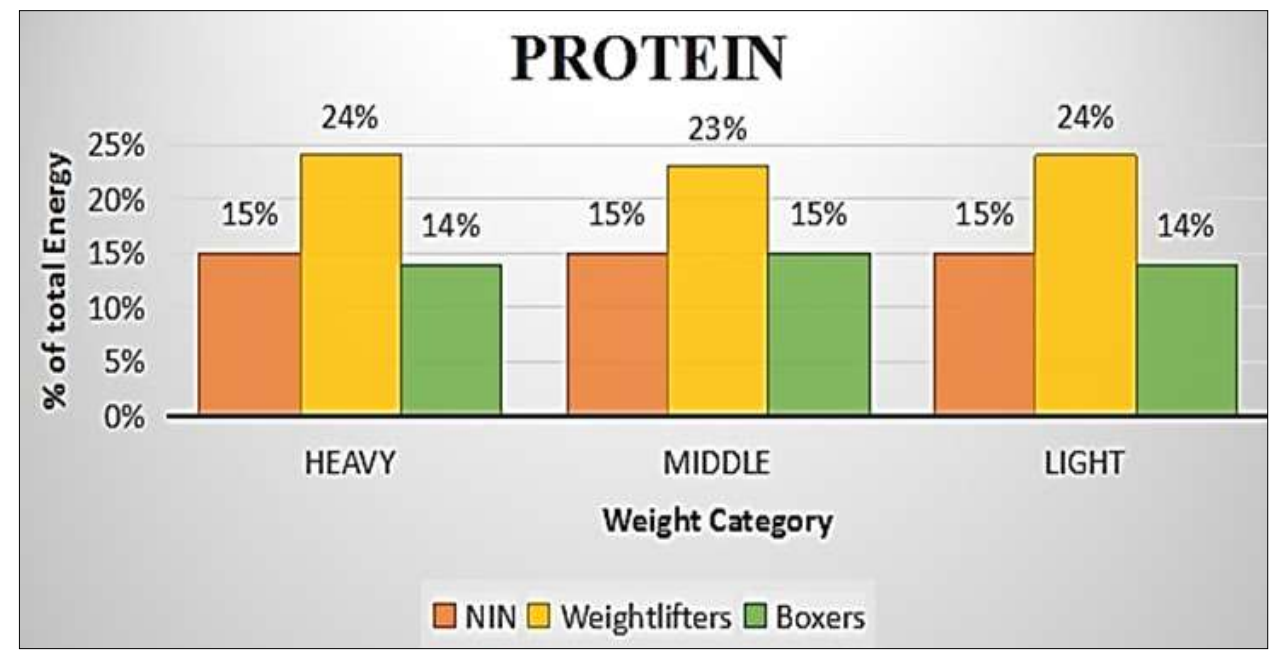

Fig 2: Mean percentage of protein intake of total energy of boxers and weightlifters with the NIN recommendation

Figure-2 show the mean percentage protein intake of total energy was high in all categories of weightlifters compared to boxers and the recommended value. The protein intake was adequate in middle weight category boxers and moderate in high \& light weight category boxers.

Figure 3: mean percentage of Fat intake of total energy of Boxers \& weightlifters with the NIN recommendation

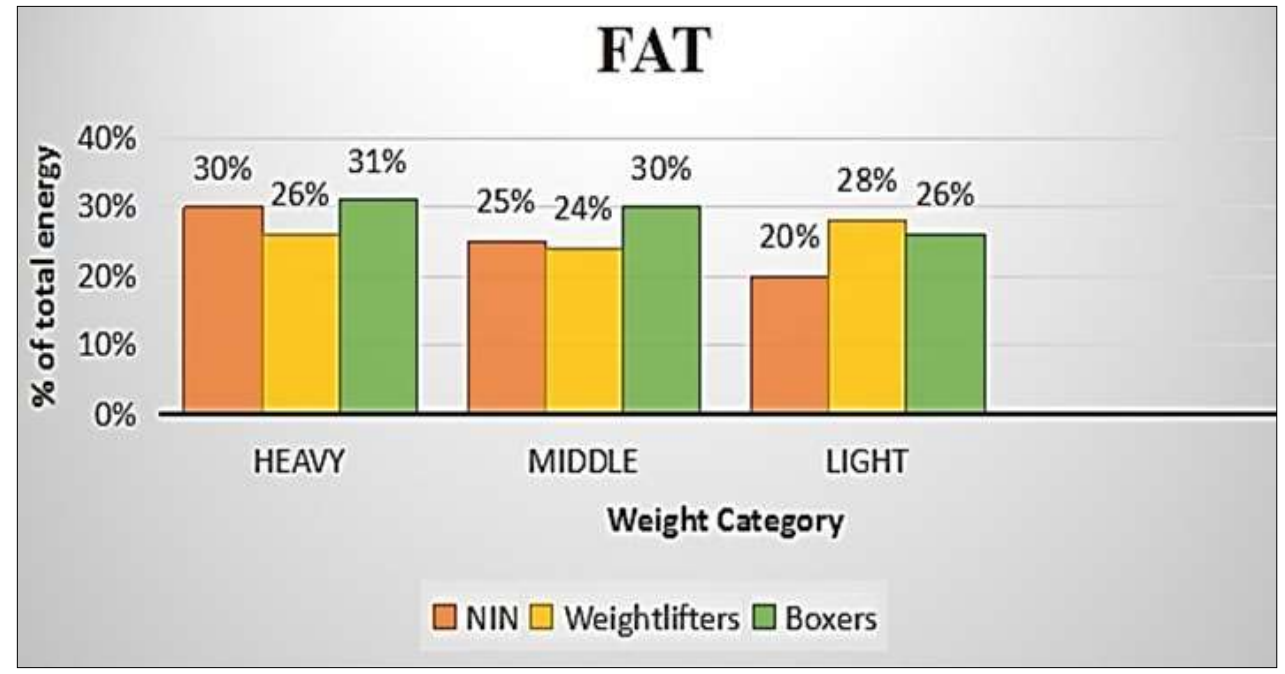

Fig 3: Show the mean percentage fat intake of total energy was high in light weight category of weightlifting and it was high in all categories of boxers 
Table 3: Comparative table of energy and macronutrients intake between weightlifters $(\mathrm{N}-22)$ and boxers $(\mathrm{N}-23)$

\begin{tabular}{|c|c|c|c|c|c|}
\hline S. No. & Variable & Group & Mean & t-value & $p$-value \\
\hline 1. & Energy & Weightlifters & 64.1091 & 5.154 & $.000^{*}$ \\
\hline & $($ Kcal/kg/d) & Boxers & 45.5087 & 5.14 & $.000^{*}$ \\
\hline 2. & Protein & Weightlifters & 3.6818 & 9.98 & $.000^{*}$ \\
\hline & (g/kg/d) & Boxers & 1.7217 & 9.956 & $.000^{*}$ \\
\hline 3. & Fat & Weightlifters & 29.0864 & -0.354 & NS \\
\hline & Boxers & 29.5478 & -0.351 & NS \\
\hline 4. & Carbohydrate & Weightlifters & 7.7773 & 2.348 & $.024^{* *}$ \\
\hline & $(\mathrm{g} / \mathrm{kg} / \mathrm{d})$ & Boxers & 6.2696 & 2.316 & $.027^{* *}$ \\
\hline
\end{tabular}

*Significant at $p<0.001,{ }^{*}$ Significant at $p<0.05$, Refer values with IOC (International Olympic Committee)

Tables 3: show the comparison between weightlifters and boxers meeting the recommendation for intake of total energy, carbohydrate, protein and fat. Significant association were found in energy and protein $(p=.000)$ in of both the groups at level $(p=<.0001)$ and carbohydrate $(p=.024)$ in weightlifters and $(p=.027)$, in boxers at level $(p=<0.05)$. No significant relationship was found in fat intake.

Table 4: Comparative table of energy and macronutrients intake between weightlifters (N-5) and boxers (N-5) of heavy weight category (70$90 \mathrm{~kg})$

\begin{tabular}{|c|c|c|c|c|c|}
\hline S. No. & Variable & Group & Mean & t-value & $p$-value \\
\hline 1. & Energy & Weightlifters & 60.6400 & 3.969 & $.004^{* *}$ \\
\hline & $($ Kcal/kg/d) & Boxers & 35.6200 & 3.969 & $.007 * *$ \\
\hline 2. & Protein & Weightlifters & 3.6600 & 5.982 & $.000^{*}$ \\
\hline & $(\mathrm{g} / \mathrm{kg} / \mathrm{d})$ & Boxers & 1.3200 & 5.982 & $.002^{* *}$ \\
\hline 3. & Fat & Weightlifters & 31.7800 & 0.500 & NS \\
\hline & Boxers & 30.6200 & 0.500 & NS \\
\hline 4. & Carbohydrate & Weightlifters & 6.7200 & 2.036 & NS \\
\hline & $(\mathrm{g} / \mathrm{kg} / \mathrm{d})$ & Boxers & 5.000 & 2.036 & $\mathrm{NS}$ \\
\hline
\end{tabular}

*Significant at $p<0.001, * *$ Significant at $p \leq 0.05$, Refer values with IOC (International Olympic Committee)

Tables 4 show the comparison between weightlifters and boxers of heavy weight category meeting the recommendation for intake of total energy, carbohydrate, protein and fat. Significant association at $(p<0.05)$ were found in energy intake for weightlifters $(p=.004)$, for boxers $(p=.007)$. Protein was significant higher at $(p<0.001)$ in weightlifters $(p=.000)$ and significant at $(p<0.05)$ in boxers $(p=.002)$.fat and carbohydrates were not significant in both the groups.

Table 5: Comparative table of energy and macronutrients intake between weightlifters (N-8) and boxers (N-9) of middle weight category (60$70 \mathrm{~kg})$

\begin{tabular}{|c|c|c|c|c|c|}
\hline S. No. & Variable & Group & Mean & t-value & $p$-value \\
\hline 1. & Energy & Weightlifters & 67.9500 & 4.380 & $.001^{*}$ \\
\hline & $($ Kcal/kg/d) & Boxers & 45.2111 & 4.208 & $.002^{* *}$ \\
\hline 2. & Protein & Weightlifters & 3.7375 & 6.618 & $.000^{*}$ \\
\hline & (g/kg/d) & Boxers & 1.7444 & 6.496 & $.000^{*}$ \\
\hline 3. & Fat & Weightlifters & 28.5625 & -.505 & NS \\
\hline & Boxers & 29.7556 & -.483 & NS \\
\hline 4. & (\% of energy intake) & Weightlifters & 8.5125 & 2.075 & NS \\
\hline & Carbohydrate & Boxers & 6.2111 & 1.960 & NS \\
\hline
\end{tabular}

*Significant at $p<0.001, * *$ Significant at $p<0.05$, Refer values with IOC (International Olympic Committee)

Tables 5 show the comparison between weightlifters and boxers of middle weight category meeting the recommendation for intake of total energy, carbohydrate, protein and fat. Significant association at $(p<0.001)$ were found in energy intake for weightlifters $(p=.001)$, for boxers $(p=.002)$ significant at $(p<0.05)$. Protein was significant at $(p<0.001)$ in both the groups $(p=.000)$. Fat and carbohydrates were not significant in both the groups.

Table 6: Comparative table of energy and macronutrients intake between weightlifters (N-9) and boxers (N-9) of light weight category $(<60 \mathrm{~kg})$

\begin{tabular}{|c|c|c|c|c|c|}
\hline S. No. & Variable & Group & Mean & t-value & $p$-value \\
\hline 1. & Energy & Weightlifters & 62.6222 & 1.815 & NS \\
\hline & $($ Kcal/kg/d) & Boxers & 51.3000 & 1.815 & NS \\
\hline 2. & Protein & Weightlifters & 3.6444 & 4.967 & $.000^{*}$ \\
\hline & (g/kg/d) & Boxers & 1.9556 & 4.967 & $.000^{*}$ \\
\hline 3. & Fat & Weightlifters & 28.0556 & -.339 & NS \\
\hline & Boxers & 28.7444 & -.339 & NS \\
\hline 4. & Cof energy intake) & Weightlifters & 7.7111 & .629 & NS \\
\hline & Carbohydrate & Boxers & 7.0333 & .629 & NS \\
\hline
\end{tabular}

*Significant at $p<0.001, * *$ Significant at $p<0.05$, Refer values with IOC (International Olympic Committee) 
Tables 6 show the comparison between weightlifters and boxers of light weight category meeting the recommendation for intake of total energy, carbohydrate, protein and fat. In light weight category only protein $(p=.000)$ was found significant at $(p<.001)$ in both the groups.

Table 7: Comparative table of energy and macronutrients intake within the group of weightlifters (N-22) of heavy, middle and light weight categories

\begin{tabular}{|c|c|c|c|c|c|c|}
\hline & & Sum of squares & df & Mean square & $\mathbf{F}$ & Sig. \\
\hline \multirow{3}{*}{$\begin{array}{l}\text { Energy } \\
\text { (Kcal/kg) }\end{array}$} & Between Groups & 290.568 & 2 & 145.284 & .877 & NS \\
\hline & Within Groups & 3146.110 & 19 & 165.585 & & \\
\hline & Total & 3436.678 & 21 & & & \\
\hline \multirow{3}{*}{$\begin{array}{l}\text { Protein } \\
(\mathrm{g} / \mathrm{kg})\end{array}$} & Between Groups & .003 & 2 & .002 & .003 & NS \\
\hline & Within Groups & 10.090 & 19 & .531 & & \\
\hline & Total & 10.093 & 21 & & & \\
\hline \multirow{3}{*}{$\begin{array}{c}\text { Fat } \\
(\% \text { of energy intake })\end{array}$} & Between Groups & 62.332 & 2 & 31.166 & 1.111 & NS \\
\hline & Within Groups & 532.814 & 19 & 28.043 & & \\
\hline & Total & 595.146 & 21 & & & \\
\hline \multirow{3}{*}{$\begin{array}{l}\text { Carbohydrate } \\
(\mathrm{g} / \mathrm{kg})\end{array}$} & Between Groups & 17.755 & 2 & 8.878 & 1.205 & NS \\
\hline & Within Groups & 139.983 & 19 & 7.368 & & \\
\hline & Total & 157.739 & 21 & & & \\
\hline
\end{tabular}

Refer values with IOC (International Olympic Committee)

Tables 7 show the comparison within the group of weightlifters in all three weight categories meeting the recommendation for intake of total energy and macronutrients. There was no significance found within the group in any nutrient intake among weightlifters.

Table 8: Comparative table of energy and macronutrients intake within the group of boxers (N-23) of heavy, middle and light weight category

\begin{tabular}{|c|c|c|c|c|c|c|}
\hline & & Sum of squares & df & Mean square & $\mathbf{F}$ & Sig. \\
\hline \multirow{3}{*}{$\begin{array}{l}\text { Energy } \\
\text { (Kcal/kg) }\end{array}$} & Between Groups & 791.581 & 2 & 395.791 & 3.825 & $.039 *$ \\
\hline & Within Groups & 2069.557 & 20 & 103.478 & & \\
\hline & Total & 2861.138 & 22 & & & \\
\hline \multirow{3}{*}{$\begin{array}{l}\text { Protein } \\
(\mathrm{g} / \mathrm{kg})\end{array}$} & Between Groups & 1.754 & 2 & .877 & 2.501 & NS \\
\hline & Within Groups & 7.012 & 20 & .351 & & \\
\hline & Total & 8.766 & 22 & & & \\
\hline \multirow{3}{*}{$\begin{array}{c}\text { Fat } \\
\text { (\% of energy intake) }\end{array}$} & Between Groups & 11.945 & 2 & 5.972 & .561 & NS \\
\hline & Within Groups & 213.072 & 20 & 10.654 & & \\
\hline & Total & 225.017 & 22 & & & \\
\hline \multirow{3}{*}{$\begin{array}{c}\text { Carbohydrate } \\
(\mathrm{g} / \mathrm{kg})\end{array}$} & Between Groups & 13.340 & 2 & 6.670 & 4.712 & NS \\
\hline & Within Groups & 28.309 & 20 & 1.415 & & \\
\hline & Total & 41.649 & 22 & & & \\
\hline
\end{tabular}

\section{Discussion}

In the present study we compared the macronutrient intake of weightlifter $\&$ boxers with the NIN guidelines. The major findings of the study were that the energy and macronutrients intake of boxers were low in compression to weightlifters. The classifications of sports by NIN are based on weight and the nutritional recommendations are same for the weight category sports. The energy intake of light weight category of both the groups were more in comparison to heavy and middle weight category as, the recommendation of energy is less in light weight category in compression to middle and heavy weight category. Valliant et al. also reported that a group of female collegiate volleyball players failed to meet dietary requirement for energy, carbohydrate and protein ${ }^{[20]}$. Another finding was that in weight lifting, as well as in other modalities categorized by body weight, the athletes usually limit the energy consumption in order to reduce body weight, with the purpose to adapt to the category of lower weight, trying thus, to take advantage over the other competitors ${ }^{[3]}$. Many female athletes restrict energy intake to lose body fat to improve performance or archive a desired body size [19]. Similarly, in another study the female lacrosse athletes were failed to meet energy requirement as their mean intake was $32.1+7.9 \mathrm{k} . \mathrm{cal} / \mathrm{kg}^{[11]}$. Concerning the eating habits of a group of jockeys ${ }^{[14]}$, it was observed that, regardless the sex, the average daily intake was below the daily needs, since $72 \%$ of the sample even reduced the food consumption at the day of the race. In school wrestlers, it was observed that $24 \%$ of the evaluated athletes decreased the diet calories at least once a week and $10 \%$ did that on a daily basis. Since these athletes dedicate a large part of their time to training and competitions, the low caloric consumption will be able to result in nutritional problems, which is not compatible with health and optimum performance ${ }^{[3]}$.

In the current study the carbohydrate (in percentage of energy) intake was low in all weight category of weightlifter and it was low in light weight category of boxers with the recommendation. A research has suggested that carbohydrate intake is often the main macronutrient restricted by individuals to meet body composition goals [21]. Carbohydrates consumption is highly recommended before, during and after exercise. Before exercise, simple carbohydrates drink or gel should be ingested to avoiding the possible counter back of hypoglycemia. During exercise, the carbohydrates consumption saves glycogen, delaying fatigue appearance and results in lower circulating indices of proinflammatory cytokines ${ }^{[13]}$. After exercise, the intake of carbohydrate drink is essential in order to accelerate the muscular and hepatic glycogen resynthesize ${ }^{[12,13]}$. Especially in high intensity sport modalities, the carbohydrates metabolism is higher. Restrictions in carbohydrates consumption will lead to reduction in the glycogen storages, 
which will impair the work ability, leading to fatigue. Considering that weight lifting also represents a high intensity intermittent activity, it is clear that the suitable $\mathrm{CHO}$ consumption is important to high quality training.

Protein intake (percentage of energy) in the present study was found high in weightlifters of all weight category. The protein intakes were significantly higher in weightlifters then boxers. The mean protein intake was almost same 3.66, 3.73, 3.64 in heavy, middle and light weight categories respectively of weightlifter and 1.32, 1.74, 1.95 in heavy, middle and light weight categories respectively of boxers .we can say that the dietary protein intake pattern was same in all weight categories but the intake should be according to body weight. Another study suggested that when energy availability is low (due to energy restriction aiming for weight loss), protein intake may be increased to preserve muscle mass ${ }^{[10]}$. Another study supports the finding, additional protein needs for active individuals may increase to $2-3 \mathrm{~g} / \mathrm{kg}$ of body weight per day when training during energy restriction ${ }^{[12]}$.

In the study the fat intake was found high in all weight category of boxers and light weight category of weightlifters. The results from another study reveal that the mean daily fat intake of wrestlers is $106.3 \%$ of RDA ${ }^{[15]}$. Based on current evidence, it may be prudent to recommend that dietary fats should account for $20-35 \%$ of calories - conforming to The American College of Sports Medicine recommendations for athletes ${ }^{[16]}$. Dietary fat helps with the absorption of critical fat-soluble vitamins and carotenoids. It provides also an essential fuel source and increases growth needs of adolescents ${ }^{[17]}$.

\section{Conclusions}

This study was aimed to determine the macronutrients intake of boxers \& weightlifters. From this study it was concluded that the energy intake was low among boxers in comparison to weightlifters. The carbohydrate intake was low in weightlifters in comparison to boxers except light weight category, protein \& fat intake was high almost all weight category, it shows that the weightlifters are consuming more protein \& fat through their diet in comparison to carbohydrate. Weightlifters are using protein \& fat as main energy source. Boxers were consuming high fat. The dietary analysis of boxers and weightlifters shows that the players were making inappropriate nutrient choices so Adequate nutritional counseling and monitoring is required to address the nutrient intake to the players for optimizing their performance.

\section{References}

1. Thomas DT, Erdman KA, Burke L. American College of sports medicine joint position statement. Nutrition and athletic performance Med Sci Sports Exerc 2016;48(3):543-68,501-28.

2. Kerksick CM, Wilborn CD, Roberts MP, Smith Ryan, Kliener SM et al. ISSN Eeercise \& sports nutrition review update: research \& recommendation. J Int Soc sports nutri 2018;15(1):38.

3. Book-Nutrition and hydration guidelines for excellence in sports performance 2007, P22-24.

4. Jager R, Kerksick CM, Campbell BI, Cribb PI, Wells SD, Skwiat TM et al. International society of sports nutrition position stand: Protein and exercise $\mathrm{J}$ inter Soc sports nut 2017, P1-25.

5. Achten J, Halson SL, Moseley L, Rayson MP, Casey A, Jeukendrup AE. Dietary carbohydrate content during running training routs in better maintenance of performance and mood. State $\mathbf{J}$ applied Phys 2004;96(4):1331-40.

6. Moran DS, Heled Y, Arbel Y, Israell E, Finestone AS, Evans RK et al. Dietary intake and stress fractures among elite male combat recruits J Intern Soc sports Nut 2012, P1-7.

7. Green MW, Roger PJ, Elliman NA, Gatenby SJ. Importance of cognative performance associated with dieting and high levels of dietary restraint Phys Beh 1994;55(3):444-52.

8. American Dietetic Assocation, American college sports medicine, Dietitions of Canada. Joint Position Statment, Nutrition and athletic performance. Med Sci sports Exerc 2000, P2130-45.

9. Umeda T, Nakaji S, Shimoyama T. Adverse effects of energy restriction on myogenic enzyme in judoists. J sports Sci 2004;22;329-38.

10. Helms E, Zinn C, Rowlands D, Brown SA. Systematic review of dietary peotein during caloric restriction trained lean athletes. Int $\mathbf{J}$ sports Nutr Excer Metabolism 2014;24(2);27-38.

11. Andrew R, Jagim Hannah Z, Brad C, Patrick S, Haety Richard S, Chand Kersick M. Nutrient status and perceptions of energy and macronutrient intake in group of collegiate female lacross athletes. Journal of the international society of sports nutrition 2019;16:43.

12. Sarah LJ, Gina T, Aaron C, Thomas K, Samuel R, Adrienne F. Regina Dietary intake of professional Australian football athlete surrounding body composition assessment, B. Journal of the nutritional society of sports nutrition 2018;15:43.

13. Book/article-Jeremy E Simatos Nutritional intake, dietary habits and physiological profile of 2004 Greek preolympic Amateur boxer team.

14. Marni E, Shoemaker Zachary M, Gillen Brianna D, Mckay Nicholas A, Bohannon Sydney M, Gibson Karsten K. Sex specific relationship among iron status, athlete performance, maturity and dietary intake in preadolescent and adolescent athletes. Journal of the international society of sports nutrition 2019;16:42.

15. Pooya D, Mitra H, Reza G, Gholamreza A, Leila D, Bijan I, Nafiseh S. Dietary behaviors and nutritional assessment of young male Isfahani wrestlers. International journal of preventive medicine 2013, PS48-S52.

16. Rodriguez NR, Di Marco NM, Langley S. American college of sports medicine position stand-Nutrition and athletic performance 2009;41:709-731.

17. Petrie HJ, Stover EA, Horswill CA. Nutritional concerns for the child and adolescent competitor. Nutrition 2004;20:620-31.

18. Book-Sastri BVR, Gopalan C, Balasubramanian SC. Nutritive value of Indian foods. Indian Council of Medical Research 2010.

19. Book/article-Melinda Manore M. The female athlete: Energy and nutritional issues. Sports science exchange, Gatorate sports science institute 2017;258(175):1-5.

20. Valliant MW et al. Nutrition education by registered dietitian improves dietary intake and nutrition knowledge of a NCCA female volleyball team. Nutrients 2012;4(6):506-16.

21. Burke L, Cox G, Cummings N, Desbrow B, Guidelines for daily carbohydrate intake-Do athletes acheive them? Sports Med 2001;31:267. 